\title{
Review of Package Warning Labels and Their Effect on Consumer Behaviour with Insights to Future Anticounterfeit Strategy of Label and Communication Systems
}

By John Spink, Jay Singh and S. Paul Singh

This paper investigates and reviews literature regarding a range of topics important to the research question - the themes apply across all the topics. The topics include label and package warnings, including tamper-evident features, to review their effect on the consumer behaviour of changing usage or purchase decisions. This information was then applied to gain insight into anticounterfeit product/package efforts. Based on this research, it appears that there is value for brand marketers to enhance their anticounterfeit efforts and consumer confidence by utilizing warning labels and information labels on their labels or packages. Currently, consumer perception of a domestic counterfeit product threat (promoted as genuine products), even for pharmaceuticals by healthcare professionals, although increasing has still been very low. Generally, the consumers believe and expect that the product purchased from retailers is safe and genuine. The study reviewed many key warning and label communication areas: consumer behaviour review, technical specifications, anticounterfeit, tamper evidence/tamper resistance, over-the-counter drugs, alcohol, cigarette, nutrition food and nutrition supplements. To complete the insight on communicating with the consumer, a review of label legibility was included. Before brand marketers consider adding anticounterfeit warning labels, extensive consumer behaviour research should be conducted in areas such as fear appeals and involuntary risk outrage.

KEY WORDS: packaging; labels; warning; anticounterfeit; communication; fraud 


\section{INTRODUCTION}

There is great attention, financial spending, confusion and lack of scholarly research on applying solutions to the rising counterfeit product problem. It is estimated that US businesses lose $\$ 200$ billion annually to counterfeiting and that $10 \%$ of the cosmetics and toiletries worldwide are counterfeit. ${ }^{1}$ In addition, the legal concept of 'foreseeable hazard' seems to be increasing in corporate risk management awareness. If sold by weight, producing and distributing fake CD or DVDs are five times more profitable than selling illegal drugs. ${ }^{1}$ These acts of producing counterfeit or fraudulent products and packages constitute an illegal activity under most national laws regulating commerce and trade.

Although there has been a great deal of research in both consumer behaviour influences of warning statements and technical package label specifications, there is limited scientific work specifically integrating and meshing both study areas. A systems approach where no single component works alone has been effectively used in many product groups, for example in tamper evidence (TE) and tamper resistance (TR). Further developments are occurring in the anticounterfeit strategy systems approach as mass serialization (unique product code for every product) and auto-identification use of sophisticated barcodes and radio frequency identification (RFID) mature. Many global corporations today coordinate functional groups of corporate security, packaging, intellectual property law, brand management and supply chain management. Various studies have shown the impact of RFID and improved tracking and traceability in a wide range of products including apparel, consumer goods, health and beauty aids and fresh produce (fruits and vegetables) in a global marketplace that often wants brand-name products to reduce risk of fake, fraudulent, adulterated or counterfeit products. ${ }^{2}$ However, limited research or activity has been conducted in considering warning labels as an anticounterfeit measure. 
This research reviewed various sources of literature regarding label and package warnings, including tamper-evident features, to review their effect on the consumer behaviour of changing usage or purchase decision. The focus was on the concept of the package/product counterfeit threat. This research focuses on the consumers who are intending, and expecting, to buy genuine product. Reviewing or proposing anticounterfeit packaging component features as well as reviewing intellectual property rights or copyright issues or warnings is beyond the scope of this research.

There are many disparate themes and topics that assist in choosing the most effective and efficient countermeasure. This research project was structured to review the applicable concepts one at a time, which is also consistent with the previous published research that is focused by topic.

- Themes

o Package, label and consumer behaviour

o Labels, warnings and content communication

o Anticounterfeit package components and labels

o Tamper-evident and tamper-resistant components and labels

- Specific topics

o Over-the-counter (OTC) medications, components and labels

o Alcohol warning labels

o Cigarette labelling, warnings

o Nutrition - food labelling 


\section{METHODS}

This research project provides insight based on evidence available in academic research studies. The research focused on various published papers in journals, which are shown in Table 1 . This research reviewed specific publications and gave preference to refereed, peer-reviewed journals with supporting news articles or trade publication articles, where supporting information was important.

The research project begins with a review of several key themes including package, label and consumer behaviour; labels, warnings and content communication; anticounterfeit package components and labels; and tamper-evident and tamper-resistant components and labels. Several specific topics will be reviewed in the following section.

\section{Package, label and consumer behaviour}

Packaging systems include labels, package features based on size and shape, primary package, outer package, overwrap (such as tamper-evident sleeve), pricing or promotional material, shipping container and palletized product. The following excerpts are from findings of several previous research studies.

A variety of individual different variables affect whether or not someone notices, encodes, comprehends, and complies with a warning. ${ }^{3}$ As the US population grows older, an emerging complication will be age-related with challenging perceptual and cognitive abilities. $^{3}$

A warning label ignored is not effective. ${ }^{4}$

\section{[Insert Table 1]}

Many warning labels are the result of legal or regulatory requirements. Warnings are intended to prevent mishaps such as injury, illness or damage to property. It is assumed that 
if properly warned against a hazard, consumers are less likely to have adverse incidents with a product. Some who study warnings, however, question whether this is really the case. Research conducted by the Failure Analysis Associates, California, USA, suggests that 'a warning is unlikely to change behavior if a person fails to read or understand it, or is unmotivated or unable to change'.5,6

A critical risk communication concept is how consumers actually process information. General consumer behaviour research states that consumers frequently employ two to three key points when making a purchase decision and have difficulty comprehending or coping with a risk that eliminates the warning as one of those decision factors. To increase the effectiveness of warnings, multiple information mediums should be used.

The optimum labeling system is an information provision system with 4 components: 1 . point-ofpurchase displays, 2. advertisements, 3. labels and 4. package inserts. ${ }^{7}$

Further review of various studies concludes that 'product type' actually has a low correlation to the attention a warning label receives, and 'vividness-enhancing characteristics' and warning location were more significant features. The dimensions that were studied were attention, reading and comprehension, recall, judgment and behavioural compliance. ${ }^{8}$ There is even evidence that reading warning labels differs for males and females, including variations in adolescent and adults of each sex. The variation is due to differences in socialization gender traits that carry over to the underlying propensity to use product labels. $^{9}$

The consumer cognitive (thinking versus feeling) biases are important to consider because 'harms of omission over harms of direct action' conflict with the need to deal with many risks at once (multiple risks in one product or among products purchased in the entire buying 
trip), and the multiple risks can conflict and lead to an error in estimation of the magnitude or probability of risk.10

The ability for consumers to make comparisons between products is crucial, which includes price marks (price sticker), active ingredients and quantity, dosage, and the like. ${ }^{11}$

Consumers truncate information searches to just the information on the front of labels, and those who truncated the messages associated a 'halo effect' ('rating the product higher on other health attributes not mentioned in the clam') or a 'magic bullet' attribute (attributing inappropriate health benefits to the product). ${ }^{12}$ The same was witnessed for environmental claims such as 'ozone-free'. ${ }^{13}$

It was of interest to review the response to nutrition label regulations and how they are justified and understood. ${ }^{12}$

- Consumers are unable to understand nutrition information on the package (e.g. the nutrition facts panel).

- Even if consumers can understand the nutrition facts panel, in practice, they ignore it and instead rely only on the health claim.

- When both sources of information are read, the presence of a health claim alters how consumers weigh nutrition information from different parts of the package in such a way that incorrect nutritional inferences are made about the product.

Addressing risks, but de-emphasizing them in relation to the benefits, can lead to selective retrieval and possibly re-interpreting evidence in light of advertising (consider erectile dysfunction ads where half the ad is an attractive scene with a voice-over mentioning a long list of warnings and risks that are numerous and warned as potentially very severe). The research found that when customers have actual physical experience with the product, the ad helps recall of those physical experiences. When consumers do not have experience with a product, the ads were the context in which consumer 
behaviour was engaged. In essence, when consumers did not have personal experience with a product, the ad was the product experience.

Overall, the experiments suggested that consumers do not need very convincing evidence before they begin to believe advertising claims. ${ }^{14}$

The issues of believability of a warning are also crucial to the label's effectiveness, and a key feature is 'probabilistic versus definite' statements on the labels, ${ }^{15}$ for example, 'warning smoking has been linked to lung cancer' versus 'warning - poison - induce vomiting if swallowed'.

There are predictions that consumer use of nutrition labels is increasing. The familiarity and experience in understanding the warning information in one product group will equate to expertise in interpreting label information in other more complex or even lower-involvement product groups. ${ }^{16}$

Labels, warnings and content communication

Extensive research on OTC pharmaceutical warning label text and wording specification has been conducted at the Michigan State University School of Packaging. ${ }^{17}$ This research clearly supports a performance standard versus the 'prescriptive' approach pursued by the US Food and Drug Administration (FDA). The research used proprietary equipment that determined that font style is as important a factor as font size, where a 5.5-point font typeface (FDA minimum, 6point font) was more legible than a much larger 9-point font FDA-compliant design. ${ }^{17,18}$ In addition, some font styles are more effective than others, and it focused on legibility in low-light situations to simulate the environment or other physical eyesight limitations. ${ }^{19}$ Verdana was found to be a more legible font style than Gills Sans or Univers Ultra Condensed (Figure 1). ${ }^{18}$ Regarding label text content, too much information can lead the low-involvement consumer to skip reading or understanding and interpreting the label. A recent study indicated that optimal 
message communication is provided when a short claim on the front of a package was provided and more detailed instructions were available elsewhere on the outer package. ${ }^{20}$ In addition, warning labels with simple words were easier to read and more efficiently understood by subjects with a wide range of education level - 50\% of US adults have sixth-grade or lower reading levels $^{21}$ - common and clear signal words are critical ${ }^{22}$ and, when they actually read the warning labels, consumers were able to generally determine risks quickly and accurately. ${ }^{23}$ Additional research emphasizes a need for warnings in several languages and other strategies for 'special needs’ populations. ${ }^{24}$ Research revealed that consumer label information preferences vary widely. $^{25}$

\section{[Insert Figure 1]}

In other research, contrary to the hypothesis, 'familiar' word messages were not unequivocally 'easier' for the subjects to read. This continues to support the elementary consumer behaviour theory that 'uninvolved consumers are less likely to seek information' because it is plausible that the commonly used English language phrases are not 'familiar' to consumers in the warning label context. ${ }^{17}$ In other words, the finding supports the idea that consumers are not (regularly) reading OTC labels. Further adding to the complexity of the issue, other research revealed that retailer-applied price tags and security antitheft tags were frequently applied over the FDAregulated 'drug facts box’ (50.4\%), specifically over the warning (23.6\%) and the active ingredients (9.3\%) and product use (4.4\%) text. ${ }^{26}$ The security tags were considered necessary to prevent pilferage because it is estimated that OTC medications are the most pilfered drugstore items. $^{26}$

A summary of key warning label components are noted: 
- 'Signal word: A single, attention-getting word (e.g., "Warning!”) should appear at the head of the warning in large type size as an indicator that the label contains important information, ${ }^{15,22}$

- 'Hazard statement: A single statement should identify the nature of each relevant hazard'15

- 'Consequences: The warning should describe the resulting outcomes of ignoring the hazard(s), ${ }^{15}$

- 'Instructions: The warning should specify the behaviors that may result in injury or damage (i.e., how to avoid the hazard). The warning should also describe appropriate remedial or emergency treatment $^{15}$

\section{Anticounterfeit package components and labels}

The state-of-the-art anticounterfeit actions are centred on applying multiple layers of tamperevident and hard-to-reproduce anticounterfeit packaging features such as colour-shifting inks, holographic stickers, holograms with wireless tracking devices, ${ }^{27}$ reverse-printed tamper-evident shrink bands, nano-coatings that can only be detected by proprietary or laboratory equipment, layers of micro-laser printing, micro-laser etching and so on. ${ }^{28,29}$ To help consumers selfauthenticate product, the tobacco industry has used tear tapes and advanced film wrapping for years. Leading pharmaceutical companies have discussed many initiatives for package components, for track-and-trace authentication throughout the distribution and supply chain networks and for central databases to verify lot and product codes. Emerging markets such as India and China are flooded with counterfeits in some product groups with as much as $15 \%$ to $50 \%$. Suppliers of products such as printer cartridges have developed programs where consumers can check lot and product codes on the brand owner's company website. ${ }^{29}$ A key observation regarding anticounterfeit package features or labels for pharmaceuticals or other products is that they do not utilize warning labels for either the risk of counterfeit products or directions on how to 
authenticate the product. Although consumer groups and product manufacturers highly recommend processes for consumers to authenticate suspect products, there is an absence or limited information or warning labels on packages. ${ }^{29}$

\section{Tamper-evident and tamper-resistant components and labels}

The most studied and active area of security packaging is in TE and TR. Before covering the warning label aspect, it is important to establish a review of the root features and objectives of the packaging components. The goal of TE is for the consumer to notice 'evidence' that the package has been tampered with. The goal of TR is to make tampering more difficult. ${ }^{30}$ In 1994, the FDA regulated that pharmaceutical products be tamper-evident, not just tamper-resistant. Consumers are now aware of potential product tampering, which makes package durability, to not look tampered after routine handling, a package requirement. ${ }^{31}$ In addition, the tamperevident features of the product on the shelf must be noticeable by the consumer. An inductionsealed bottle (a sealed membrane over the bottle opening, then the cap is placed over that membrane) does not indicate TE until the consumer opens the cap. In that instance, if the membrane is removed with no residue, a consumer might not realize that a tamper-evident feature was even supposed to be there.

Extensive work has been conducted in tamper-evident/tamper-resistant and child-resistant (CR) packaging for the past 20 years at the Michigan State University School of Packaging. ${ }^{32}$ This research focused on packaging components of shrink band, membrane seal, plastic overwrap, blister package and vacuum button. 'Successful tamper evidence requires consumer education, packages that are easy for consumers to diagnose, a limited variety of systems, a reduction rate of package change, better instructions for use. ${ }^{33}$ Even with state-of-the-art packaging components and procedures, research found that $12 \%$ to $50 \%$ of consumers were unable to detect tampering. ${ }^{34}$ 
In addition, 'consumers were largely unaware of the tamper resistant statements now mandatory on pharmaceutical products' ${ }^{34}$ It is important to investigate root causes for consumers' perception that a package was or was not tampered because common misconceptions have been experienced. $^{35}$

The amount of security required to 'resist' tampering depends on the objective to thwart the casual or malicious tamperer. ${ }^{36} \mathrm{~A}$ 'casual' tamperer is a consumer who only wants to taste the peanut butter before buying, and a 'malicious' tamperer is one whose intent is to inflict harm. There is forensic value to the tamper-evident features because a tampered package can be studied to evaluate the level of sophistication of the tamperer and to estimate where in the supply chain the tampering occurred. For instance, a 1986 New York Times article, regarding the Tylenol poisonings referred to forensic evidence that led them to believe that the product was tampered with after it left the manufacturer. ${ }^{37}$ Four years earlier, in 1982, the industry experienced a tampering scare with the Dristan product, where a tampered capsule was sent to the NY City Health Department. ${ }^{38}$ An additional prevention step can be for brand marketers to engage packaging professionals to evaluate TR and TE and to provide an overview across the product line or to understand opportunities with new packaging features. ${ }^{38}$

Research still emphasizes a need for greater TR as well as 'improved signaling of tampering to the consumer, ${ }^{39}$ As early as 1988, the marketing community started understanding the risks surrounding malicious tampering events. ${ }^{40}$ The major difference between recent and historical package tampering is the scope of potential harm. Faced with the possibility of mass consumer poisonings, marketers should develop preventive programmes to forestall criminal intervention. Strict liability is the dominant legal theory when consumers have been injured, but negligence liability is the primary approach available. ${ }^{40} \mathrm{~A}$ single tampering incident or scare can change 
package designs instantly. In 1991, a Sudafed capsule tampering resulted in mass questioning of the package form of capsules and a rapid retail preference for non-openable doses. ${ }^{41}$ Another example of a response from a scare is that after the 2005 baby food 'ricin' poisoning, many baby food manufacturers added a second tamper-evident/tamper-resistant feature of the shrink band (the first tamper-evident feature was the vacuum 'pop’ lid).

To provide additional insight and cover some well-researched applications, the research project reviews several key topics including Over-the-counter medication components and labels; Alcohol warning labels; Cigarette labelling, warnings; and Nutrition - food labelling. Many specific food examples are included because of the extent of the research on this specific label warning communication and marketing. Over-the-counter medication components and labels Additional research has found that 1.94 million hospital admissions per year are due to drug noncompliance [Bix L. 2000, Michigan State University, East Lansing, Michigan, USA, unpublished data]. For an OTC drug label's message to be successfully delivered, consumers must notice it, encode it, comprehend it and comply with it. Failure at any of the stages of consumer/label interaction reduces message effectiveness. The four steps of this process have been studied extensively in recent years because of many societal changes already presented. Although the knowledge base is substantial with regard to this topic, it is still lacking. No single model or format indicates what facilitates focal attention, successful encoding, complete information processing, elaborate comprehension and compliance in elderly consumers, and many findings contradict one another [Bix L. 2000, Michigan State University, East Lansing, Michigan, USA, unpublished data]. 
The FDA is focusing regulation on improving the legibility of OTC drugs by specifying design elements of the labels. For example, legibility research went further and developed equipment and a procedure to quantify the legibility of various printing fonts. Legibility of OTC labels is of particular significance because it is a major factor in allowing products to be switched from a prescription to OTC classification, which usually has a much higher volume. ${ }^{42}$ Another study quantified misuse and even 'off- label recreational' use by teenage consumers. ${ }^{43}$ The goal of the recreational use was similar to illicit drug use to 'get high' or 'get drunk faster' ${ }^{43}$ A retail audit found that although the font size of the brand name and key features and benefits increased with package size, the warnings and indication still remained the same font size. ${ }^{26}$ Print size has been a common theme for significantly improving the information acquisition of OTC labels. ${ }^{44}$ 'No substantial effects on knowledge acquisition performance from the white space manipulations [area around the words, within a warning text box] were found', although larger print and its associated additional white space did exhibit the maximum information acquisition. ${ }^{44}$

\section{Alcohol warning labels}

A 1-year and 5-year study of alcohol warning label effects on 10th and 12th graders determined that an 'initial novelty of the warning labels appears to have led to some initial positive effects' ${ }^{45}$ 'The novelty of the warning label however, appears to have worn off [at 3.5 years after exposure] ${ }^{45}$ Because the 'Alcohol Beverage Labeling Act' went into effect in 1989, most of the research has focused on short-term effects of the warnings. ${ }^{46}$ The study investigated by directly asking 'How Effective Are Alcohol Warning Labels?' The answer was that not only does the impact of the warning wane after introduction, but 'those with a favorable attitude toward alcohol consumption tend to disbelieve specific instance warnings' ${ }^{46}$ Regarding the efficacy of alcohol warning labels and messages, evidence suggests that their effectiveness is limited to low 
awareness or knowledge gain and little or no changes in the perceived risks associated with alcohol use, let alone changes in attitudes or behaviours. This may be because people already know the content of warning labels and messages, become desensitized after hearing repeatedly about the risks associated with alcohol use or fail to find the information personally relevant. ${ }^{46}$

Consumers seem to be more aware and act on warning labels when their health condition or status changes, such as becoming pregnant. ${ }^{47,48}$ A very significant research project explored the 'Noticeability of Warnings on Alcohol Beverage Containers' ${ }^{49}$ Noticeability of warning information is important because if a warning is not seen, it cannot realistically have any effect on its target audience. The quality or efficacy of a warning's content is irrelevant if the warning is never noticed or read. The results of this experiment show that various design parameters of actual alcohol container warnings influence the noticeability of the mandated warning. The variables having the greatest influence were the subjective measures: noticeability of the warning, noticeability of the government warning and label clutter. The warnings considered to be less noticeable (noticeability of the warning) were those that had shorter signal word length and greater clutter on the labels. The warnings that had a less noticeable signal word (noticeability of the government warning) were those that had a shorter signal word length and fewer lines. Also, the containers that were considered more 'busy' or 'cluttered' were those that had fewer labels on which to place information and a smaller area (in square inches) for the warning. ${ }^{49}$

Another researcher found that 'cognitive responses (rational thought responses, not feelings) in diagnosing the persuasive effectiveness of the warning label' have been under-considered. ${ }^{48,50}$ The process of the consumer forming counter-arguments is critical to the warning's effectiveness, once the consumer is persuaded to actually read the warning. Also, initial attitudes towards consumption of the product played a key role in a consumer's believability of the warning. The message itself 
carried $70 \%$ more 'thought' of the warning, as compared with the source of authority (e.g. Surgeon General). ${ }^{48}$ A key proposed insight from this study was to rotate various warnings to try to capture the attention of the consumer. In 2006, this concept of rotating marketing slogans or labels is employed by several food and beverage companies (e.g. Heinz Ketchup name, Molson Canadian beer back label, Taco Bell comments on salsa packets). Similar research findings applied to warnings on print and television advertisements, package label warnings ${ }^{51}$ and wall posters. $^{52}$

\section{Cigarette labelling, warnings}

In 1964, the US Surgeon General reported a link between cigarette tar and lung cancer, and then in 1966, the Federal Trade Commission encouraged cigarette companies to note their tar levels on the package labels. ${ }^{53}$ A dramatic market share shift occurred where cigarettes with $\leq 15 \mathrm{mg}$ of tar grew from 0\% in 1960 to 68\% in 1992 (pre-1960, the average cigarette had $37 \mathrm{mg}$ of tar). Although the labelling and research led to far lower average levels of tar, 'In a 1980 Roper survey, $36 \%$ of smokers thought that their low-tar cigarette did not significantly increase a smoker's risk of disease over that of nonsmokers, and another 31\% were not sure if this was the case'.53

In addition, cigarette industry documents speak to this issue: 'We have evidence of virtually no quitting among smokers of those brands, and there are indications that the advent of ultra low tar cigarettes has actually retained some potential quitters in the cigarette market by offering them a viable alternative. ${ }^{53}$ Research of teen smokers concluded that 'starker, briefer and more direct messages' (e.g. 'Smoking Can Kill You') were enhanced by a plain white package versus putting them within the copy of a full label. More 'technical, longer and vaguer' messages did not increase effectiveness. ${ }^{54}$ Graphic and vivid warning labels were effective, leading to $20 \%$ of the study 
participants smoking less (1\% reported smoking more). The negative emotions were not considered psychologically extreme. $^{55}$

Nutrition - food labelling

Health claims. 'Healthy' is a term that has inspired reams of scholarly research and is a package label content term originally regarded as 'true', but now consumers are desensitized to the unique value of a 'healthy' product. ${ }^{56}$ Consumer research has indicated that nutritional label reading is only a small part of a consumer's total search criteria, ${ }^{57}$ although the underlying trend is that nutritional food labels have statistically significantly increased the healthy eating patterns of Americans. ${ }^{58}$

A health claim characterizes the relationship between a food nutrient and the risk of a disease or health-related condition. ${ }^{59}$ These claims can alert consumers to a product's health potential by stating that certain foods - as part of an overall diet - may reduce the risk of certain diseases. ${ }^{60}$ Such efforts, however, are not always successful. ${ }^{20,59-63}$

Congress passed the Nutritional Labeling and Education Act in 1990. This Act regulated 'healthy’ claims for total fat, saturated fat, cholesterol or sodium versus specified limits. In addition, the total 'healthy' value of a product must be followed, for example where a product low in fat but high in sodium cannot make healthy claims. ${ }^{64}$

Product labels are the consumer's primary means of receiving information about nutritional or health claims. Consumers also receive nutritional and health information from point-of-purchase displays, educational campaigns, as well as from personal contact. It was found that consumers can be sceptical of new health claims, so the public sector (academia, government agencies, public health communities and the medical field) has a key role in lending credibility to new claims. ${ }^{63}$ Consumers are very unlikely to recognize 'incongruences' between claims or nutrient 
levels of one additive in comparison with another additive, as well as cumulative claims on the 'healthy' essence of a food. ${ }^{65}$

It is felt that the nutritional label regulation is justified by considering the following: ${ }^{64}$

- First, consumers may lack the competence to comprehend nutrition information on the product label (i.e. they may not understand whether $8 \mathrm{~g}$ of fat in a product is low or high).

- Second, health claims may influence consumers' processing of nutrition information on the product label even if they have the ability to understand nutrition information.

- Third, consumers may decide to rely solely on the health claim and ignore the nutrition information altogether.

The amount of consumer involvement with the product does seem to play a role in seeking and understanding information labels. In a study of initial introduction of air-tight, vacuum-packed fresh beef, consumers overcame the concern regarding the unusual brownish-red colour of the beef for the higher-involvement, more expensive meats such as fillet mignon. ${ }^{66}$

Health claims are most influential when the consumer is aware of nutritional properties or attributes (vitamin A content or level of saturated fat) and knowledge of how these attributes affect health (vitamin A is good for eyesight, low saturated fat is good for controlling cholesterol) ${ }^{63}$ It does appear that the location of the information is important because consumers trust health claims made on a label and are more sceptical of claims in advertisements. ${ }^{48}$ 'Additive-free' labelling. Research found several product groups where the 'additive-free' phrase (cholesterol-free, etc.) has led consumers to believe a product is more healthy, for example stating a vegetable oil has 'no cholesterol' is actually true of the entire vegetable oil category, but the single brand established a marketing competitive advantage. ${ }^{67}$ 
Overall, the results suggest that displaying common but previously neglected attributes has both brand-level and product-level category effects. At the brand level, studies suggest that using the narrow 'cholesterol-free' tag on brand labels results in the following:

- Feature-absent inferences (if the attribute of 'additive-free' is not mentioned, this brand must not have it) about those brands that do not mention the attribute

- Choices in favour of brands displaying the attribute

- Increased accessibility of the target attribute for those subjects who believe that the target attribute is atypical in the product category

These results support the FDA position that this type of 'nutrient-free' claim appears to mislead consumers in a narrow product category definition context. Therefore, the FDA ruling that disallows the practice of using this type of 'free' nutrient claim on foods that are inherently free of the nutrient can benefit consumers in those contexts. ${ }^{68}$ Other studies suggest that broader 'nutrient-free' claims are less deceptive and help inform low-knowledge consumers regarding the typicality of the nutritional attribute for all brands in the product category. ${ }^{68}$

That being said, few product-level groups use the 'nutrient-free' claims ${ }^{68}$ Because the brand marketers cannot use the 'nutrient-free' claim as a point of differentiation, if every company in a product-level group used the claim, it would be a point of parity and a waste of precious advertising space on the package label.

New additives or processing. The packaging trade press has discussed the situation where warning label regulations can raise concerns when, scientifically, none are present. For example, labelling of 'organic' or 'bovine somatotropin (bST)-free foods' can lead consumers to believe that non-organic or bST-containing foods are scientifically significantly inferior. ${ }^{6}$ The same was 
noted for irradiated foods, scientifically safe levels of pesticide residues, bioengineered foods and also acrylamide found in fried foods like French fries. ${ }^{6}$

Examples. Bovine somatotropin or bovine growth hormone. (Note: Bovine growth hormone is referred to as bST, rbST, BGH or rbGH. $)^{69,70}$ An example of the Nutrition Labeling and Education Act (21 U.S.C. 301) is a ban on stating 'BGH-free', where the science-based risk is still in question and the statement of BGH-free may create a risk perception where no risk may be $_{\text {present. }}{ }^{71}$

Negative labeling [an alternate phrase for "nutrient/additive-free” discussed above] of traditional foods (e.g., milk is claimed "from cows not treated with rBST") should be discouraged. Such labeling implies the food has a special attribute which which it does not have. Negative labeling may mislead and confuse consumers, and provides no additional public health protection. It is predicted that the label statement of "GMO-free" would lead consumers to perceive a risk, or at least a warning. ${ }^{67}$

Regarding bST, the results of consumer behaviour studies found that different personal situation characteristics 'correlated with different levels of awareness, risk perceptions and selfprotective actions'. ${ }^{72}$ Specifically identified were characteristics of hereditary health history, ethnicity, educational level, sense of control over their lives and identification with environmental groups. ${ }^{72}$ In addition, the study finds a correlation with consumers who identify with environmental groups as being more self-protective against the use of bST or other 'nonnatural' products. This concept may be a marketing tool for the environmental product manufacturers. The study also found that consumers 'responsible for the health of others' (typically the primary grocery shopper for their children) demonstrated a higher motivation to avoid the bST product. ${ }^{72}$

The study confirms the complex 'multifaceted nature of consumer risk behavior.' Also, 'that there are not only separate stages of risk perceptions associated with different levels of 
awareness and action but also that different factors seem to influence these stages and, as such, it is possible to predict what stages consumers might be in by their characteristics’ ${ }^{72}$

Margarine. During the initial market growth of margarine, the dairy industry lobbied not only for prohibiting yellow white margarine but also for trying to mandate the use of non-customary butter colours of pink, red and black. In this case, the dairy industry tried to use these 'negative attribute' to their marketing advantage as a source of initially unacceptable consumer preference. $^{67}$

Saccharin warning labels. The effect of saccharin warning labels on consumer behaviour was reviewed for the soft drink category (75+\% of the US saccharin sales). Although sales initially slowed in some consumer sub-segments, the warning labels had no apparent effect on overall sales. 'While the sales of saccharin-containing products did not decrease overall, the warning may have been a success in informing the public of a risk and then letting consumers make more informed decisions', ${ }^{73}$

Genetically modified foods and organisms. For genetically modified foods and organisms (GMO), the negative-labelling/nutrient-free statement of 'GMO-free' has led to concerns from the users of GMO products. 'A label that discloses the use of genetic engineering techniques can add significantly to the product costs of certain foods, particularly processed foods that are produced from pooled fresh fruits and vegetables'. ${ }^{67}$

In 2002, Oregon did not pass Measure 27, which required labels for genetically modified foods. A complex series of concerns surrounded the vote, but an underlying trend was that consumers did have (realized they had) a concern for what was in the food they were eating. ${ }^{74}$ Essentially, choosing staple foods like breakfast cereal, milk, tomatoes and potatoes was elevated 
from a low-involvement/lowknowledge to a high-involvement purchase/high-knowledge purchase.

Interestingly, some manufacturers who utilize genetically modified foods or organisms are steering away from using the common 'GMO' acronym and are using ' $\mathrm{GM}$ ' ${ }^{75}$ The GM acronym may be less associated with 'genetically modified', and in a low-involvement/low-knowledge situation, consumers may be confused by the icon 'General Motor’s' very recognized abbreviation GM.

Nutrition, supplements. The Dietary Supplement Health and Education Act went into effect in 1994, and it created the class of products known as 'supplements' - neither food nor drug. The Dietary Supplement Health and Education Act allows supplement manufacturers to 'use structure function claims, such as, "Helps promote a healthy emotional balance," on supplement package labels without premarket FDA approval, provided the legislative disclaimer is included ${ }^{75}$ This right to state such claims was upheld by the courts citing the first amendment free-speech protection. 75,76

A 2005 study of 'supplements' in the Journal of Consumer Affairs pursues many consumer behaviour concepts that can be applied to a wide range of products: ${ }^{75}$

- Preliminary research suggests that priming consumers to pay particular attention to certain aspects of a product label can significantly influence use and understanding of the label.

- Consumers do not discern between 'structure-function claims' (e.g. helps maintain cardiovascular function) and 'disease claims' (e.g. prevents development of malignant tumours).

- Consumers did respond to 'express disease claims' (e.g. for prevention of osteoporosis). 
- Consumers with high involvement for health or disease prevention had a higher degree of belief in the function and disease claims than those with low involvement.

The key finding was that consumer's existing and distantly related beliefs can override product or label information. On the positive side, some consumers may try effective innovative products, and on the negative side, some consumers 'may eliminate a potentially helpful product from their evoked set [the set of choice alternatives activated directly from memory] ${ }^{75,77}$

\section{DISCUSSION}

The purpose of this research was to examine open-source literature regarding label and package warnings, to review their effect on the consumer behaviour or changing usage or purchase decisions and to apply the insights to the package/product counterfeit threat. The research found that consumers do not generally read warning labels. Within regulations, brand marketers place negative risks or warnings in ways that minimize the impact on the consumer's purchase decision. Print and media advertisements utilize the selective retrieval of information quite effectively. Brand marketers also know, and leverage, the findings that consumers truncate searches on front labels to the detail on the back labels - consumers either rated the effectiveness higher or the risk lower than stated in the claims. In addition, consumers often associated the 'magic bullet' effect where a consumer attributes other, not stated, benefits to the product. The issue of believability of warning labels is crucial to helping consumers avoid injury of a potentially dangerous, if misused, product. Specifically noted for alcohol warning labels, the message itself carried more weight than the endorser, even when the endorser was the Surgeon General. For a warning label to be effective, consumers must first notice a label, then read it, then comprehend it and then recall the instructions during future uses (when they may not read the label). There is evidence that alcohol warning labels are effective when first implemented but that the impact wanes over time. Although the 
research does state that consumers are more aware of warning labels as their health status changes, for example, becoming pregnant or as health deteriorates, more direct and harsher messages were most effective - e.g. 'Smoking Can Kill You.'

The nutrition 'additive-free’ claims have very interesting consumer behaviour consequences that can be applied to other product groups. It was clearly defended that previously non-highlighted product attributes (e.g. 'Zero Trans Fats', 'Whole Grains’) did bring new positive attention to the product. At the same time, 'GMO-free' (without genetically modified foods and organisms) claims created a consumer awareness of the concept and a perception that if GMO-free was a good feature, products that did not say GMO-free were more risky or significantly inferior. The nutrition supplement marketers are successfully using structure-function claims ('helps promote a healthy emotional balance') to the point that consumers do not discern between these and direct disease claims ('prevents skin cancer'). Also important is that consumers with high-involvement interests in health claims or disease prevention tended to have a higher level of belief in the claims than those with low involvement.

The research also found many ways to communicate the information and risks effectively to the consumer.

\section{Technical and structural packaging and label overview}

Label specifications such as font style and font size are key to readability of warnings. Research found that the 'Verdana' font style is superior for warning and information text. In addition, for the many low-involvement/low-information products, an appropriate balance of emphasizing the warning must be reached to communicate risks but not overwhelm the consumer to the point that they ignore the warning. Clearly, uninvolved consumers are less likely to read the warnings, and generally, the research supports that consumers do not read even OTC drug warning labels. Clear 
signal words and warning images are critical, as are clearly differentiated text - many alcohol warnings meet regulations but are hard to find on the packages. In addition, more common warning text/phrases across all product groups may lead consumers to recognize the phrases in the context of warnings. A series of 'special needs' should be considered, such as the visual acuity of the ageing population and warnings in several common languages.

\section{Anticounterfeit warning label applications}

Based on this research, it appears that there is value for brand marketers to enhance their anticounterfeit efforts by utilizing warning labels and information labels. A key is focusing on the consumers who are intending, and expecting, to buy a genuine product. Currently, consumer perception of a domestic counterfeit product threat, even for pharmaceuticals by healthcare professionals, is increasing but still very low. Generally, consumers believe that a product from their retailer is safe and genuine. Current anticounterfeit efforts by brand marketers are focused on strengthening the control of the supply chain and in adding multiple complex layers of anticounterfeit packaging features. For package labels, there is no evidence that brand marketers are including counterfeit warnings or processes to authenticate the product. Brand marketers do sometimes reference the ability to authenticate product on their websites or in direct contact with large business-to-business customers.

Many of the anticounterfeit multiple-layered packaging features are coordinated or included with other features, such as with tamper-evident packaging components (e.g. anticounterfeit complex printing on a typical tamper-evident shrink band). For specific high-counterfeit-risk products, the multi-purpose feature is very cost effective and also very complex, which adds additional barriers for the counterfeiter trying to copy the package or product. 
Although return on investment is still not clear, there are many questions about harmonization and standardization of systems, and there are very real concerns about security assurance of the codes, and consumer products appear to be leading towards a mass-serialization concept where every single package has its own unique product code. This mass-serialization concept will be critical to enabling the automatic-identification RFID initiatives specified by the US FDA.

From an international perspective on general standards, in 2009, the International Standards Organization (ISO) addressed the product counterfeit threat by forming the Technical Committee 247 Fraud Countermeasures and Controls. The first step in 2009 was to create Product Committee 246 Authentication tools, which are slated to become ISO Standard 12931. The next action item is to develop an international standard for Security Assurance for the Document and Product Security Industry [based on the American National Standards Institute (the US international standards body) and the North American Security Products Organization, ANSI/NASPO-SA-2008]. ISO TC 247 is also developing a report to harmonize the terminology. Specifically, for food ingredients, the US Pharmacopoeia joined with the Food Chemicals Codex and created the Food Ingredient Intentional Adulteration Expert Panel. For the potential impurities in counterfeit or fraudulent product, the organization is developing overviews (Chapters), reference test specimens (Reference Standards) and technical specifications (monographs).

With some of the mass-serialization coding schemes, advanced application algorithms are applied to a 26-field alpha-numeric codes, which makes it 'impossibly difficult' for a counterfeiter to guess any series of even two codes. The only legitimate codes the counterfeiter could determine are codes read off legitimate product (if the codes are laser etched or two-dimensional matrixes, the technical counterfeiter could determine the genuine 'code'). If both genuine and counterfeit codes were 
authenticated, the database, and thus the consumer, would be alerted that one of the two products was a fake.

The mass-serialized codes would allow and possibly motivate consumers to authenticate their product; in addition, widespread authentication of product would help the brand marketers in their investigations against bogus product. Multiple data points of validation and quick identification of rouge product would be helpful. Brand marketers and retailers are working very hard to tighten the control of their supply chains, but the huge profitability of the occasional elusive hit-and-run nature of product counterfeiting fuels its continued growth.

\section{CONCLUSION}

Based on this research, it appears that there is value for brand marketers to enhance their anticounterfeit efforts by utilizing warning labels and information labels. An anticounterfeit warning label could communicate to the consumer that there is a risk of counterfeit product and that they should register or authenticate their product. To maintain clarity, it is recommended to stick with structure-function claims (e.g. 'helps promote a healthy emotional balance') versus direct disease claims (e.g. 'prevents skin cancer'). That being said, critical pharmaceutical products do have options to effectively use direct disease claims (e.g. 'WARNING: Fake Heart Medicine Exists, Immediately Authenticate Your Product. See Your Pharmacist or product.com/authenticate'). A conceptual example is included Figure 2.

The counter-argument that counterfeiters would just not put the warnings on their counterfeited product so the warnings do not get to the affected consumer does not hold up. The majority of consumers are trying to, and expecting to, buy genuine product through a legitimate channel. For a counterfeiter who is focused on infiltrating the genuine supply chain with either stolen or occasional products to not be detected, the package and labels would need to be exact, 
including the anticounterfeit warning. That being said, the counterfeiters have been known to fake authentication website links. Brand marketers have systems in place to monitor package and label authenticity, and the teams include international and US customs and international and US investigators, in addition to internal product testing protocols.

\section{[Insert Figure 2]}

There is a very real danger that the new anticounterfeit warnings could inadvertently bring negative publicity or negative consumer perception to the brand or product or to even create an inherent fear of the brand or the product. But with care and understanding of warnings and information labels from other product groups, there is a high likelihood that the anticounterfeit warning labels would be effective and even be leveraged to increase brand trust. A key will be giving the consumer a process to immediately satisfy their curiosity or fear - a way to authenticate. The anticounterfeit warnings have a real possibility of creating competitive advantages and consumer goodwill, as the nutrient-free claims have attained.

An objective will be to give the consumer incentive to continue to (or automatically) authenticate and not have the impact of the label wane to the point where consumers have had so many 'positive' confirmations that they perceive a very low risk and stop authenticating the product.

Access to authenticate the codes is required, but this also creates a fraud opportunity if the counterfeiters can covertly gather legitimate codes. The counterfeiters could then use those harvested legitimate codes to apply to counterfeit packages. For example, a non-line-of-sight system, such as RFID, that allows retailers and distributors to identify and check codes also provides the counterfeiters with the fraud opportunity to harvest those same genuine codes. To 
assure availability and security, it may be necessary to develop separate serialized codes for consumers and retailers.

\section{LIMITATIONS}

This research did not study the effect of pre-cautionary and warning labels that are required by law for products and packaging for chemicals, hazardous materials, flammable, poisons, etc. Such warning and labelling information has been covered in various national and international regulatory agencies. ${ }^{78}$

In addition, before brand marketers consider adding anticounterfeit warning labels, extensive consumer behaviour research should be conducted in areas such as fear appeals and involuntary

risk outrage. ${ }^{79,80}$ In addition, serious consideration to the potential responses and risks posed by counterfeiters must be reviewed [Spink and Moyer, 2011, Michigan State University, East Lansing, Michigan, USA, unpublished data]. In addition, the economic impact of the full additional costs associated with implementing and managing mass serialization and automatic-identification innovations should be followed to review how and when anticounterfeit warning labels will benefit the safety and security of the consumers without deteriorating brand-recognized product sales.

\section{REFERENCES}

1. Naim M. Illicit: How Smugglers, Traffickers, and Copycats Are Hijacking the Global Economy. Doubleday: New York, 2005.

2. Singh P, McCartney M, Singh J, Clarke R. RFID research and testing for packages of apparel, consumer goods and fresh produce in the retail distribution environment. Journal of Packaging Technology and Science 2008; 21(2): 91-102. 
3. Rousseau GK, Lamson N, Rogers WA. Designing warnings to compensate for age-related changes in perceptual and cognitive abilities. Psychology \& Marketing 1998; 15(7): 643.

4. McIntire MS, Angle CR, Sathees K, Lee PS. Safety packaging - what does the public think. American Journal of Public Health 1977; 67(2): 169.

5. Greenberg EF. The legal impact - warning. Packaging Digest 1997; 34(5): 18-22.

6. Greenberg EF. Should labels reflect everything that's on our minds? Packaging Digest 2003; 40(9): 38.

7. Bettman JR, Payne JW, Staelin R. Cognitive considerations in designing effective labels for presenting risk information. Journal of Public Policy \& Marketing 1986; 5: 1.

8. Argo JJ, Main KJ. Meta-analysis of the effectiveness of warning labels. Journal of Public Policy \& Marketing 2004; 23(2): 193.

9. Mangleburg TF, Grewal D, Bristol T. Socialization, gender, and adolescent's self-reports of their generalized use of product labels. The Journal of Consumer Affairs 1997; 31(2): 255.

10. Baron J. Cognitive biases, cognitive limits and risk communication. Journal of Public Policy \& Marketing 2004; 23(1): 7.

11. Langrehr FW, Langrehr VB. Consumer acceptance of item price removal: a survey study of Milwaukee shoppers. The Journal of Consumer Affairs 1983; 17(1): 149.

12. Roe B, Levy AS, Derby BM. The impact of health claims on consumer search and product evaluation outcomes: results from FDA experimental data. Journal of Public Policy \& Marketing 1999; 18(1): 89.

13. Maronick TJ, Andrews JC. The role of qualifying language on consumer perceptions of environmental claims. The Journal of Consumer Affairs 1999; 33(2): 297. 
14. Hoch SJ, Ha Y-W. Consumer learning: advertising and the ambiguity of product experience. Journal of Consumer Research 1986; 13(2): 221.

15. Heaps CM, Henley TB. Language matters: wording considerations in hazard perception and warning comprehension. The Journal of Psychology 1999; 133(3): 341.

16. Stanley LR. A market test of consumer response to information disclosure. Journal of Public Policy \& Marketing 1991; 10(2): 202.

17. Bix L. Toward a Performance Standard for Typeface Legibility: The Lockhart Legibility Instrument. PhD Thesis, Michigan State University, MI, USA, 2001.

18. Bix L, Lockhart H, Selke S, Cardoso F, Olejnik M. Is x-height a better indicator of legibility than type size for drug labels: research from Michigan State University School of Packaging, East Lansing, MI, USA. Packaging Technology \& Science 2003; 16(5): 199-207.

19. Bix L. The Effect of Subject Age on Legibility. MS Thesis, Michigan State University, MI, USA, 1998.

20. Wansink B, Cheney MM. Leveraging FDA health claims. The Journal of Consumer Affairs 2005; 39(2): 386.

21. Lepkowska-White E, Parsons AL. Comprehension of warnings and resulting attitudes. The Journal of Consumer Affairs 2001; 35(2): 278.

22. Wogalter M, Vigilante W Jr. Effects of label format on knowledge acquisition and perceived readability by younger and older adults. Ergonomics. 2003; 46(4): 327.

23. Wogalter MS, Silver NC. Warning signal words: connoted strength and understandability by children, elders, and nonnative English speakers. Ergonomics 1995; 38(11): 2188.

24. Torres IM, Gelb BD, Noriega JL. Warning and informing the domestic international market. Journal of Public Policy \& Marketing 2003; 22(2): 216. 
25. McCullough J, Best R. Consumer preferences for food label information: a basis for segmentation. The Journal of Consumer Affairs 1980; 14(1): 180.

26. Sansgiry SS, Bix LL, Clarke RH, Pawaskar MD. Drug information obscured on over-thecounter medication labels by external tags. Drug Information Journal 2005; 39(2): 159.

27. Passariello C. Holograms tell fake from Fendi; as knock-offs get better, makers of luxury goods reach for high-tech defense. Wall Street Journal 2006, p. B.1.

28. Spink J. Overview of counterfeit threat to the food industry. Paper presented at the Quarterly Meeting, State of Michigan’s Agriculture \& Food Protection Strategy Team (Bioterrorism), 2006.

29. Spink J. Review of anti-counterfeit packaging measures/processes/technologies for emerging markets. Research Paper, Michigan State University, School of Packaging, Anticounterfeit Research Group, 2006.

30. Hinds MC. US sets up rules on drug packages to bar tampering. New York Times 1982, p. A.1.

31. Fuhrman E. Pick me up, I’m wonderful! Candy Industry 2003; 168(1): 51.

32. Iwaszkiewicz RA II. An Evaluation of Tamper-Resistant Packaging: A Method for Measuring Tamper-Evidence. MS Thesis, Michigan State University, MI, USA, 1991.

33. Lockhart H. Tamper-Evident Packaging, the Wiley Encyclopedia of Packaging Technology. John Wiley \& Sons: New York, 1986; 628-631.

34. Adams D. Tampered packs - consumers can't tell. Packaging News (Haymarket Publishing Services) (Aust.) 1998; 36(1): 30-31.

35. Lockhardt H, Richmond M, Sneden J. Tamper evident packaging. Consumer influence tamper-resistant packaging is it really? Packag. Eng. 1983; 28(7): 91-99.

36. Pechey R. Product tampering a real danger in U.S. Packaging Engineering 1987; 3(1): 14-15. 
37. McFadden RD. Two bottles of poisoned Tylenol were shipped by same distributor. New York Times. Packaging Week 1986, p. A.1.

38. Treaster JB. Letters contain threats to tamper with Dristan. New York Times 1982, p. B.1.

39. Stilwell EJ, Rudolph SE. Strategies for foiling tamperers. Packaging 1989; 34(7): 39.

40. Morgan FW. Tampered goods: legal developments and marketing guidelines. Journal of Marketing 1988; 52(2): 86.

41. Meier B. After latest scare, U.S. is reviewing use of drug capsules. New York Times 1991, p. 1.28.

42. Morris LA, Lechter K, Weintraub M, Bowen D. Comprehension testing for OTC drug labels: goals, methods, target population, and testing environment. Journal of Public Policy \& Marketing 1998; 17(1): 86.

43. Ellen PS, Bone PF, Stuart EW. How well do young people follow the label? An investigation of four classes of over-the-counter drugs. Journal of Public Policy \& Marketing 1998; 17(1): 70.

44. Wogalter MS, Brems DJ, Martin EG. Risk perception of common consumer products: judgments of accident frequency and precautionary intent. Journal of Safety Research 1993; 24(2): 97.

45. MacKinnon DP, Nohre L, Pentz MA, Stacy AW. The alcohol warning and adolescents: 5-year effects. American Journal of Public Health 2000; 90(10): 1589.

46. Hae-Kyong B. Analyzing the impact of the liquor industry's lifting of the ban on broadcast advertising. Journal of Public Policy \& Marketing 1998; 17(1): 132. 
47. Hankin JR, Sloan JJ, Sokol RJ. The modest impact of the alcohol beverage warning label on drinking during pregnancy among a sample of African-American women. Journal of Public Policy \& Marketing 1998; 17(1): 61.

48. Andrews JC, Netemeyer RG, Durvasula S. The role of cognitive responses as mediators of alcohol warning label effects. Journal of Public Policy \& Marketing 1993; 12(1): 57.

49. Laughery KR, Young SL, Vaubel KP, Brelsford JW Jr. The noticeability of warnings on alcoholic beverage containers. Journal of Public Policy \& Marketing 1993; 12(1): 38.

50. Andrews JC, Netemeyer RG, Durvasula S. Believability and attitudes toward alcohol warning label information: the role of persuasive communications theory. Journal of Public Policy \& Marketing 1990; 9: 1.

51. Barlow T, Wogalter MS. Alcoholic beverage warnings in magazine and television advertisements. Journal of Consumer Research 1993; 20(1): 147.

52. Kalsher MJ, Clarke SW, Wogalter MS. Communication of alcohol facts and hazards by a warning poster. Journal of Public Policy \& Marketing 1993; 12(1): 78.

53. Cohen JB. Smokers' knowledge and understanding of advertised tar numbers: health policy implication. American Journal of Public Health 1996; 86(1): 18.

54. Goldberg ME, Liefeld J, Madill J, Vredenburg H. The effect of plain packaging on response to health warnings. American Journal of Public Health 1999; 89(9): 1434.

55. Hammond D, Fong GT, McDonald PW, Brown S, Cameron R. Graphic Canadian cigarette warning labels and adverse outcomes: evidence from Canadian smokers. American Journal of Public Health 2004; 94(8): 1442.

56. Golodner LF. Healthy confusion for consumers. Journal of Public Policy \& Marketing 1993; 12(1): 130. 
57. Feick LF, Herrmann RO, Warland RH. Search for nutrition information: a probit analysis of the use of different information sources. The Journal of Consumer Affairs 1986; 20(2): 173.

58. Sung-Yong K, Rodolfo MN Jr, Oral C Jr. Food label use, self-selectivity, and diet quality. The Journal of Consumer Affairs 2001; 35(2): 346.

59. Federal Register. Food labeling: general requirements for health claims for food. Federal Register 1993; 58: 2478-2536.

60. Hurt DH, Crocco SC. Dietary fiber: marketing implications. Food Technology 1986; 40: 124126.

61. Caswell JA, Mojduszka EM. Using informational labeling to influence the market for quality in food products. American Journal of Agricultural Economics 1996; 78: 1248-1253.

62. Caswell JA, Padberg DI. Toward a more comprehensive theory of food labels. American Journal of Agricultural Economics 1992;74:460-468.

63. Wansink B. How do front and back package labels influence beliefs about health claims? The Journal of Consumer Affairs 2003; 37(2): 305.

64. Ford GT, Hastak M, Mitra A, Ringold DJ. Can consumers interpret nutrition information in the presence of a health claim? A laboratory investigation. Journal of Public Policy \& Marketing 1996; 15(1): 16.

65. Garretson JA, Burton S. On consumer attitudes, perceptions of disease-related risks, and trust. Journal of Public Policy \& Marketing 2000; 19(2): 213.

66. Eastwood DB. Consumer acceptance of new experience good: a case study of vacuum packed fresh beef. The Journal of Consumer Affairs 1994; 28(2): 300.

67. Miller HI, Huttner SL. Food produced with new biotechnology: can labeling be anticonsumer? Journal of Public Policy \& Marketing 1995; 14(2): 330. 
68. Burke SJ, Milberg SJ, Moe WW. Displaying common but previously neglected health claims on product labels: understanding competitive advantages, deception, and education. Journal of Public Policy \& Marketing 1997; 16(2): 242.

69. USDA.com. Bovine growth hormone, quick bibliography series. 2006. http://www.nal.usda.gov/awic/pubs/oldbib/qb9410. htm.

70. Yahoo.com. Yahoo.com, General web search on the terms "BST” and "bovine”. 2006.

71. Douthitt RA. Consumer risk perception and recombinant bovine growth hormone: the case for labeling dairy products made from untreated herd milk. Journal of Public Policy \& Marketing 1995; 14(2): 328.

72. Grobe D, Douthitt R, Zepeda L. Consumer risk perception profiles regarding recombinant bovine growth hormone (rbGH). The Journal of Consumer Affairs 1999; 33(2): 254.

73. Schucker RE, Stokes RC, Stewart ML, Henderson DP. The impact of the saccharin warning label on sales of diet soft drinks in supermarkets. Journal of Public Policy \& Marketing 1983; 2: 46 .

74. Grobe D, Raab C. Voters’ response to labeling genetically engineered foods: Oregon’s experience. The Journal of Consumer Affairs 2004; 38(2): 320.

75. France KR, Bone PF. Policy makers’ paradigms and evidence from consumer interpretations of dietary supplement labels. The Journal of Consumer Affairs 2005; 39(1): 27.

76. Vladeck DC. Truth and consequences: the perils of half-truths and unsubstantiated health claims for dietary supplements. Journal of Public Policy \& Marketing 2000; 19(1): 132.

77. Peter JP, Olsen J. Consumer Behavior and Marketing Strategy, 7th edn. McGraw-Hill Irwin: New York, 2005. 
78. Singh SP, Singh J. Pictorial markings and labels for safe transport and handling of packaged goods. Journal of Packaging Technology and Science 2005; 18: 133-140.

79. Spink J, Helferich OK, Griggs JE. Combating the impact of product counterfeiting [refereed article]. Distribution Business Management Journal 2010; 10(1): 6.

80. Spink J. Analysis of Counterfeit Risks and Development of a Counterfeit Product Risk Model. PhD Thesis, Michigan State University, MI, USA, 2009.

Table 1. Primary journals considered and partial summary of referenced sources.

\begin{tabular}{ll}
\hline & Primary journals \\
\hline Packaging and labelling & \multicolumn{1}{c}{ Marketing } \\
\hline Journal of Public Policy & International Journal of Marketing Research \\
Journal of Consumer Affairs & Journal of Marketing Research - could not locate \\
Packaging Science and Technology & International Journal of Retailing \\
American Journal of Public Health & Journal of Retailing \\
& Academy of Marketing Science \\
& Journal of Marketing \\
Partial summary of referenced sources (number of references) \\
Academy of Marketing Science Journal (2) & American Economic Review (1) \\
American Journal of Public Health (9) & Applied Ergonomics $(2)$ \\
Journal of Brand Protection 'Brand'(2) & Defense Council Journal (1) \\
Drug Information Journal (4) & Ergonomics (3) \\
Food Cosmetics and Drug Packaging (2) & International Journal of Advertising (1) \\
International Journal of Market Research (1) & Journal of Advertising (1) \\
Journal of Consumer Affairs (28) & Journal of Consumer Research (2) \\
Journal of Gerontology (1) & Journal of Marketing (4) \\
Journal of Pharmaceutical Marketing Management (1) & Journal of Products Liability (2) \\
Journal of Psychology (1) & Journal of Public Policy \& Marketing (41) \\
Journal of Retailing (5) & Journal of Safety Research (2) \\
New York Times (7) & Nursing Management (1) \\
Occupational Health \& Safety (2) & Packaging (2) \\
Packaging Digest (13) & Packaging Technology and Science (3) \\
Packaging Week (1) & Pharmaceutical Medical Packaging News (1) \\
Pharmaceutical Technology (2) & Professional Safety Management (1) \\
Psychology \& Marketing (2) & Wall Street Journal (2) \\
\hline & \\
\hline
\end{tabular}




\begin{tabular}{|cc|}
\hline Verdana & 11-point \\
Verdana & 8-point \\
Times New Roman & 11-point \\
Times New Roman & 8-point \\
Arial Narrow & 11-point \\
Arial Narrow & 8-point \\
Gill Sans & 11-point \\
Gill Sans & 8-point \\
Note: Univers Ultra Condensed - Not \\
\multicolumn{2}{|c}{ available } \\
\hline
\end{tabular}

Figure 1. Font style examples. ${ }^{18}$

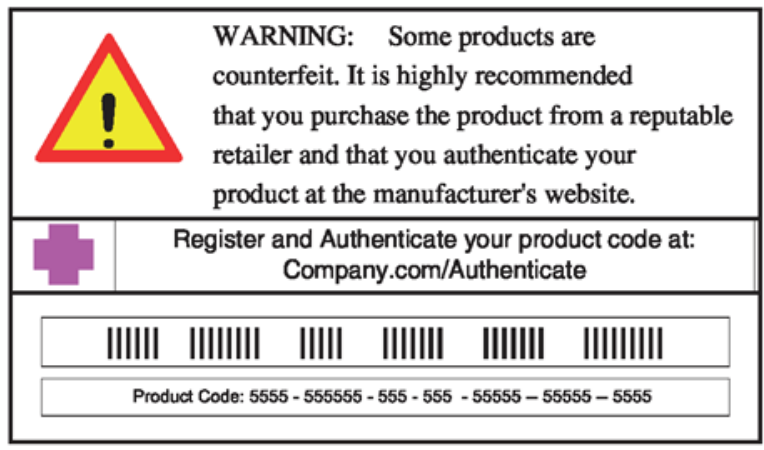

Figure 2. Anticounterfeit warning label concept. ${ }^{29}$ 